\title{
EVALUATION OF BUILDING COMFORT IN DEVELOPING COUNTRIES THROUGH CFD ANALYSIS AND TENS METHOD
}

\author{
R. COCCI GRIFONI, M. F. OTTONE \& E. PRENNA \\ School of Architecture and Design, University of Camerino, Ascoli Piceno, Italy.
}

\begin{abstract}
Building designers must consider relationships between air-flow patterns and building structure in order to achieve thermal comfort and avoid extreme air movements. Computational fluid dynamics (CFD) can simultaneously predict air flow, heat transfer and contaminant transportation in and around buildings. The role of CFD in designing buildings for developing countries is demonstrated by creating a thermally comfortable, healthy, energy-efficient building in developing countries (i.e. Buéa, Cameroon and Mkuru, Tanzania). Natural ventilation and other passive strategies were analyzed, as this is the main way to achieve better thermal comfort and reduce energy usage in buildings in tropical climate conditions. The Tomographic ENvironmental Sections (TENS) is a method of exploring a phenomenon through a large number of perspectives. Such methodology does not necessarily imply additional costs in the building's realization, an important aspect for developing countries. A building design method that supports optimization in the early design stages in countries with severe climate conditions was developed.

Keywords: Africa, comfort, computational fluid dynamics, developing countries, environmental comfort, PMV, predicted mean vote, sustainable architecture environmental thomography, sustainable architecture.
\end{abstract}

\section{INTRODUCTION}

In a young and growing context such as the one of Sub-Saharan Africa, which is based on relative political stability, steady economic activity and cultural facilities, it is possible to test a design approach that proposes technological and expressive innovations. On one hand, it moves away from the simple reproduction of formal Western constructive models; on the other hand, it uses an approach that oversteps the size of vernacular typical local buildings, introducing a sustainable methodology not only from the environmental and economic points of view, but also from the architectural language point of view. This approach places the climate and living comfort problems as central themes in defining the shapes and spaces of places and architectures [1]. It brings the technological complexity of air's beneficial effects in the living space to the design simulation (more than one space in the same building), with the belief that this issue can be tackled in a systematic way to reduce energy consumption (and therefore costs) without having to resort to sophisticated technology that has already proved to be unsuccessful. For example, this may refer to the widespread repetition of architectural models typical around the world (buildings with large glass windows and thermally inefficient coatings), whose maintenance and air-conditioning costs become unsustainable, not to mention the difficulty in finding technical staff capable of managing all the life phases of such buildings. Design experiences developed in Africa by African and European architects $[2,3]$ aim to provide a contemporary architectural language, without losing the identity and traditions of the local construction. The following case studies aim to implement this approach, entrusting a significant part of the design process to climate control based on the principles of thermodynamics, with the goal of identifying new effective forms in order to determine greater comfort. 
The first case study is set at the entrance of Buéa, the capital of the Southwest province of Cameroon, a typical small African city. Here the poverty and lack of services are evident, though signs of growth can be observed at street corners, where modern gas pumps, luxury hotels and the gates of the university campus become meeting places in a city organized along a large paved axis road. Beyond this, masonry buildings rapidly give way to wood and sheet-metal huts. This mad rush in pursuit of a lifestyle based on duplicated stereotypical patterns of a wealthy appearance, however, leaves behind a large social gap and huge environmental problems. Here, more than elsewhere, the discussion regarding sustainable development is a current issue, with the only difference being that in this case there are no precedents to follow, and there is very poor awareness among the people about the disastrous effects caused by the rest of the world from the industrial age to the present day and of which we are only recently measuring the effects.

Otherwise, the second case study goes even deeper into the matter. Fifty kilometers far from the town of Arusha, one of the most developed cities of Tanzania at the foot of Mount Kilimanjaro, rises the Masaai village of Mkuru. The Maasai were nomadic herders who have always occupied the dry land further north. Today, unfortunately, they have been forced to become a sedentary population and to occupy one of the most arid and unproductive land in northern Tanzania taking them to a state of marginalization, deprivation and poverty. Most of the Maasai community still live in villages called 'Boma'. A Boma is a settlement belonging to a family, that is a group of huts made of mud and dung arranged in a circle and characterized by a large space for livestock, the only real wealth, all protected by a fence of dry branches of acacia. In the end, the purpose of the projects is to create a set of good practices useful when there is the intention and the need to build new buildings, in a Maasai community or in any growing reality, trying to create a new architecture style that respects local traditions combining modernity in a sustainable way.

\section{COMFORTABLE DESIGN}

The Buéa Women Meeting Centre (WMC) is a public space that includes a cultural centre and facilities designed to improve the status of women, helping them in their town duties as the heads of family management (Fig. 1). The space includes a nursery, toilets, a neighbourhood marketplace, a small parking lot and a public fountain, where women can easily access a fundamental resource, water, in an orderly manner. Particular attention has been paid to

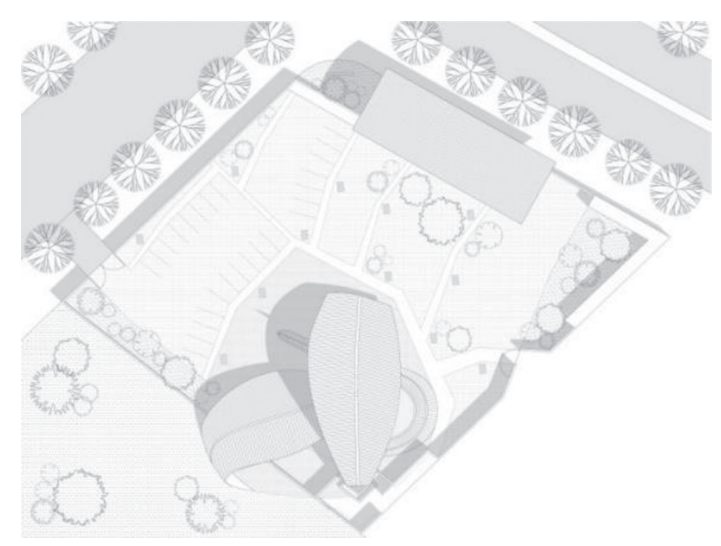

Figure 1: Women meeting centre plan. 
social aspects analysed on-site, and how architecture can solve problems that result. The lifestyle is characterised by an innate sociability and spirit of sharing that is reflected in the time that people spend outside and on the streets, thus affecting work activities such as restaurant services, street vending, small businesses, and any other activity that mostly involves women. Another element affecting daily life is the climate, important during the rainy season, when sudden strong storms flood the soil streets, blocking any type of activity.

Architectural design becomes a tool to effectively improve the living conditions and safety of the built environment, so perimeter walls play an important role in the study: the corners are de-materialised and visually open; the walled enclosure is still high but clear. Public facilities have been integrated in the structure, such as the nursery building, the market with fixed tables where girls can work more easily, sheltered from the sun and the harsh weather, the public fountain with seating where people can comfortably wait their turn. Moreover, both the drainage pavement throughout the square and the prevention of dust on pedestrian paths have been fundamental.

The concept of comfort in the usability of spaces has been introduced through small but important details. In addition, the WMC includes classrooms for adult vocational training, an auditorium, a hostel for guests at the cultural centre, offices, and a canteen. These other facilities have been specifically requested by the community, in an atmosphere of participative planning, considering the need to provide education to those who are no longer in school or who work during the day. Visiting Buéa, it is possible to understand how the auditorium is instead an urban object, it will be visible at the edges of the main roads or in the public garden; it stands as a platform covered with a light shade structure, useful for recurring public events, religious celebrations, or graduation sessions. As such, its exclusive use, even in case of rain, its fixed seats, and the possibility of hosting personalities invited to conferences, becomes a source of pride for the cultural centre.

The purpose of the design of the Boma Community Service in Mkuru (BCS) goes directly to address the basic needs of the local population as well for the WMC, despite the situation of the Masaai is more complex and the same facilities affect the development of life in the entire village (Fig. 2). The main problems stem from the lack of energy, the lack of water and

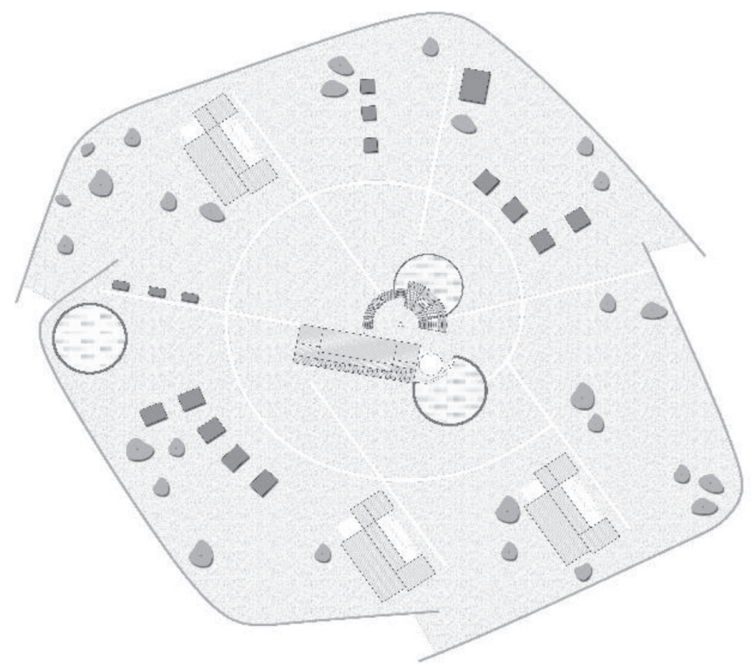

Figure 2: Boma community service plan. 
the lack of hygiene, the first cause of the spread of serious diseases that affect local communities, especially due the promiscuity with the animals they breed. For these reasons, the Community Centre includes all the basic services that are currently missing in the village. Then, in the building there is a space dedicated to cleaning and personal hygiene, a part will be used as common kitchen with a pantry and a technical room for plants. In addition, there are a number of areas open but covered by a series of canopies and large covers, on different levels of the ground, according to the functions. Dining places, for relaxing or where collective activities take place for relationship moments, festivals and rituals. Attached to the service block and the big square, there are two large circular enclosures, one for cattle and another for the vegetable garden. For rainwater collection, there are a large tank and an underground one connected to a large tub where a classical hand pump push out water for cattle during drought periods. A series of channels along the square collects rainwater with the purpose of cooling the environment, bring water to the vegetable and watering small pets in the courtyard.

\section{CLIMATE AND THERMAL COMFORT}

Buéa is a town on the slopes of Mount Cameroon, an active volcano that rises $4000 \mathrm{~m}$ above sea level, $400 \mathrm{~km}$ north of the Equator and $15 \mathrm{~km}$ from the Atlantic Ocean, which significantly affects the local climate, already perceived to be cooler and less humid at an altitude of $800 \mathrm{~m}$. All of these aspects lead to an average rainfall typical of the tropical climate in the Gulf of Guinea, up to $5000 \mathrm{~mm} / \mathrm{m}^{2}$ per year, with the peculiarity of air flows from the SSW, thanks to protection by the mountain to the North. Therefore, the year consists of the rainy season, between April and September, and the dry season, from October to March, with a peak solar radiation of $6200 \mathrm{~W} / \mathrm{m}^{2}$. Thus, the climate in Buéa tends to be humid and hot in the lower neighbourhoods (Fig. 3).
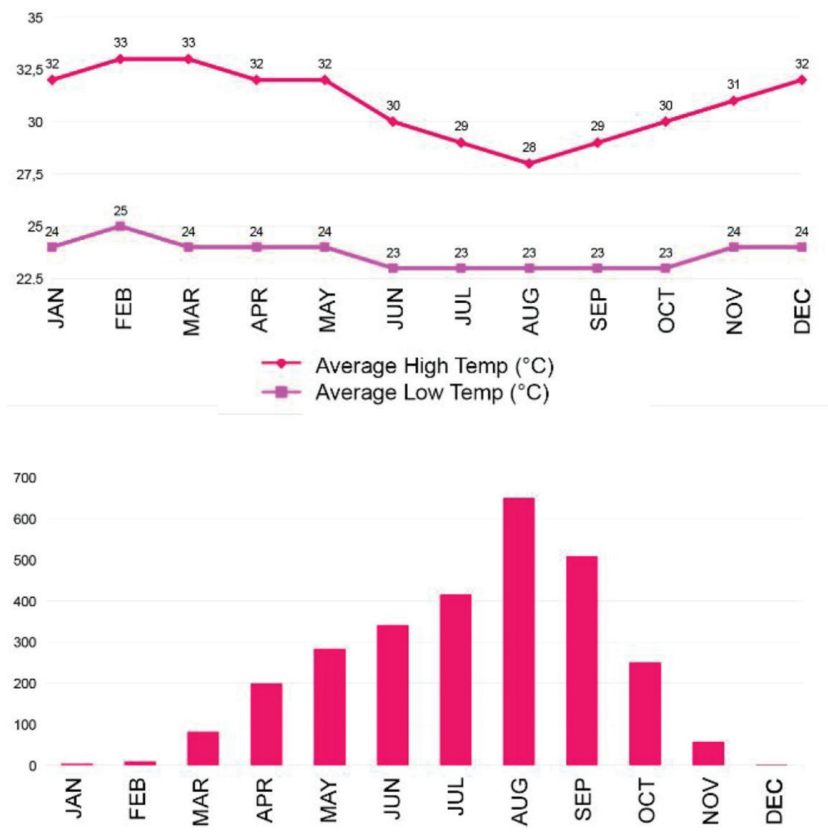

Figure 3: Plot of average temperature and rainfall in Buéa. 
Quite similar is the climate in the northern part of Tanzania, predominated by the same tropical tempered climate. Although the area lies between Mount Meru and Kilimanjaro, characterized by abundant rainfall and a temperate climate, the Maasai steppe is characterized by very rare rainfall, which determines the typical semi-arid and grassy savannah. The thermal excursion is considerable as well, changing from $28-30^{\circ} \mathrm{C}$ during the day to $12-10^{\circ} \mathrm{C}$ at night. The average annual rainfall in Tanzania is about $1000 \mathrm{~mm} / \mathrm{m}^{2}$, characterized by two prevailing seasons: the dry season and the rainy one. Rainfall is concentrated in November and December (called 'short rains') and March-May ('long rains'). January, September and October are normally the warmer months of the year.

The high mountain peaks direct the strong wind flows in the great plains of the enclosed steppe, during the cooler season from SSE while in the dry season from NE, in general, with a medium-high speed between 3 and $3.5 \mathrm{~m} / \mathrm{s}$. Relative humidity should be also taken into account, which reaches very high levels (around 90\%) in the early hours of the morning, and then it drops significantly in the course of the day up to $50 \%$ at noon (Fig. 4).

Then, through the definition of the climatic summary, the specific objectives in the study are to evaluate and characterize the thermal perception of occupants in some areas, using the predicted mean vote and predicted percent of dissatisfied. The most widely used thermal comfort index is the Predicted Mean Vote (PMV) index, which was developed by Fanger [4]. Fanger states that two conditions must be achieved to maintain thermal comfort.

The first is the combination of skin temperature and the body's core temperature, which provides a sensation of thermal neutrality. The second is the realization of the body's energy balance, which is based on the conservation of energy. The values of the PMV index range from -3 to +3 , which corresponds to the occupant's feeling, from cold to hot, while the PMV null value represents a neutral sensation. The thermal stress established by the PMV is based on the steady state of heat transfer between the body and the environment. It is an empirical equation used to evaluate the mean vote on a rating scale of thermal comfort for a large
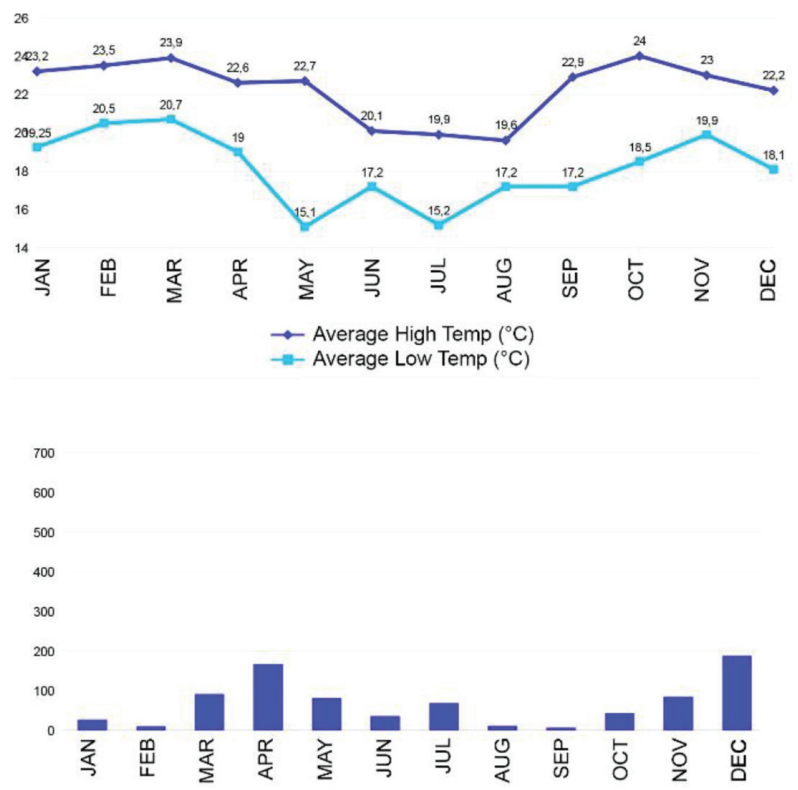

Figure 4: Plot of average temperature and rainfall in Mkuru. 


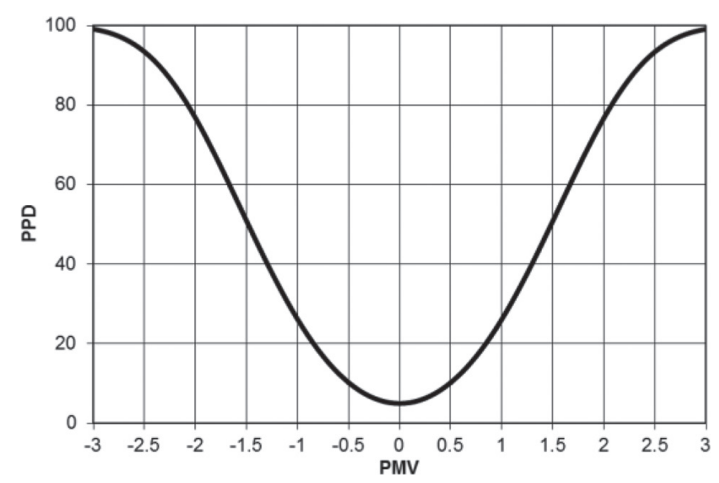

Figure 5: PPD as a function of PMV.

population of people. To develop a curve and obtain average results, people were exposed to different environments over different time spans. The term PPD represents the Predicted Percentage of people Dissatisfied at each PMV. Moving away from zero in either the positive or negative direction, the value of PPD increases. A curve has been developed to predict the percentage of people dissatisfied as a function of PMV (Fig. 5).

\section{ENVIRONMENT AND SHAPE}

The typical African outdoor lifestyle, characterised by an original biorhythm and relationship with nature, is definitely the best assumption when designing a building according to the principles of meteorological architecture [5] and biomimicry. When studied closely, the large leaves of the banana tree, an abundant local crop, are seen to perform all of the functions required of a roof. Changing the scale of the natural element and working with its flexibility, it can be transformed into an architectural element, where the main rib becomes a central compluvium and the blade lends itself to protection, shade, and shelter from the rain. The combination of three 3D elements and a 2D element on the ground make up the typical tree trunk section, ideally recalling the function of a lifeblood highway, but in reverse, i.e. no longer from roots to leaves, but as a collector of water gathered from them. This function can easily be detected from the WMC square as well, so the water tower also functions as a reference point for the public fountain. The space below the three cover leaves, which hosts the classrooms, the auditorium, the canteen and the toilets, is a limited, but not closed, environment, in which the functions are organised in a systematic way, allowing air (Fig. 6) and light to permeate the space naturally. The dynamic shape outlined above not only performs formal tasks, but also follows a more careful design based on the study of climate aspects that characterise the place.

From the analysis of data collected during the local campaigns as well as from the timeseries data from 1970 to 2000, it was possible to create a psychometric chart and a model of adaptive comfort in relation to interviews conducted among inhabitants for each case study. It is important to stress that the model generated from purely environmental data is inconsistent with the adaptive model, i.e., a project based solely on data analysis would lead to discomfort tending too much towards the cold side for a population accustomed to a tropical climate. Basing on these observations, the covering modelling was performed by applying the principles of computational fluid dynamics (CFD), which allowed for drafting and better orientation of the several elements making up the large roofs. The resulting body of the WMC, oriented 


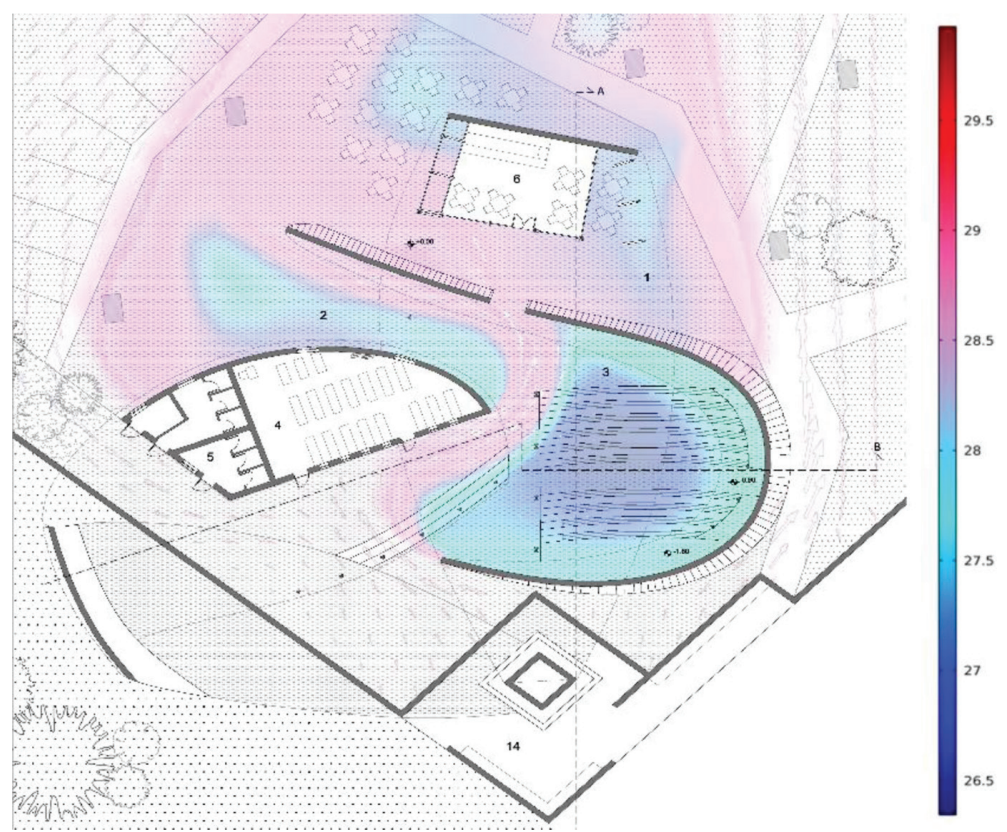

Figure 6: Pavilion tomography: temperature $\left({ }^{\circ} \mathrm{C}\right)$.

towards the South and extending to the West, captures the prevailing winds above the fence and steers them towards the hypogeum hall where, due to the chimney effect, they are expelled through the opening on the roof between the two main leaves. This organic architecture is nothing more than a blower with extraction-flow systems based on passive technologies. During short, strong rainstorms, the opening that triggers the ventilation may be shielded with a waterproof fabric that decreases the ascending action without blocking it completely. In the auditorium, where there is a greater concentration of people, cooling is implemented by a passive geothermal heat exchanger of $40 \mathrm{~m}^{2}$, buried in the garden, which brings in cold air from the vents embedded on the floor. In addition, a system of buffer rooms on the perimeter of the central hall guarantees a temperature about $4 \mathrm{~K}$ lower than the external one.

At the same way, the BCS covering provide shadow during the hottest ours of the day but its most important goal is to block the cold winds during the rainy season and facilitate the opposite input of fresh air flows in the dry season, depending on the function that takes place inside the building and the time of day. A system of reticular beams and struts supports the double coverage made of metal sheets; if to shelter just cover the windward side is needed, to trigger the convective flows inlet and outlet openings are appropriately sized and material property can help the thermodynamic effects. With basement and walls made of adobe, a great thermal mass is guaranteed on the lower part of the building and the high capacity of metal sheets to heat up easily on the top get start the convective fluxes from the ground to the ceiling, creating a comfortable air stream where it's needed.

\section{CFD MODELING AND TENS RESTITUTION}

To evaluate the fluid dynamics effects on building and consequently adjust it, a 3D model is developed and results are processed through the Tomographic ENvironmental Section 
(TENS) method [6] which make use mainly of tomography to graphically render the simulation's results. Indeed, through tomographies, namely sections on the vertical and horizontal planes of a 3D model, it is possible to define the behavior of a physical phenomena at the system's steady state. The analysis is set in a CFD software by using the laminar flow in the heat transfer module, through stationary study. Due to the complexity of the buildings, the air domain is sized on minimum dimensions to ensure the reliability of results and, in the same time, reduce the memory usage, taking care to include the boundary walls, fully integrated architectural element in the buildings and significant aerodynamic barrier. For the same reason, given the inlet and the outlet, the other sides are not considered as open boundaries but as walls, therefore, in tomographies shown, the rainbow effect next to boundaries (Fig. 7) should not to be considered because of the viscous property for fluids, which determinate the zero speed near walls.

The next step is the meshing process, an important aspect that directly affects the precision and accuracy of results. The mesh used is a free tetrahedral one, calibrated on computation fluid dynamics, automatically generated by the software relying on model dimensions. Through data collection campaigns carried out on site the prevailing direction and speed of the prevailing winds in the area are determined, thus for the WMC the inlet boundary on south is defined as a $3 \mathrm{~m} / \mathrm{s}$ and $303^{\circ} \mathrm{K}$ inflow while the opposite side, the outlet, is setted as outflow with relative pressure $\mathrm{p}_{0}=0 \mathrm{~Pa}$, while for the BCS the inlet side is setted on the north at $3 \mathrm{~m} / \mathrm{s}$ and $300^{\circ} \mathrm{K}$, fixing the south as outlet boundary.
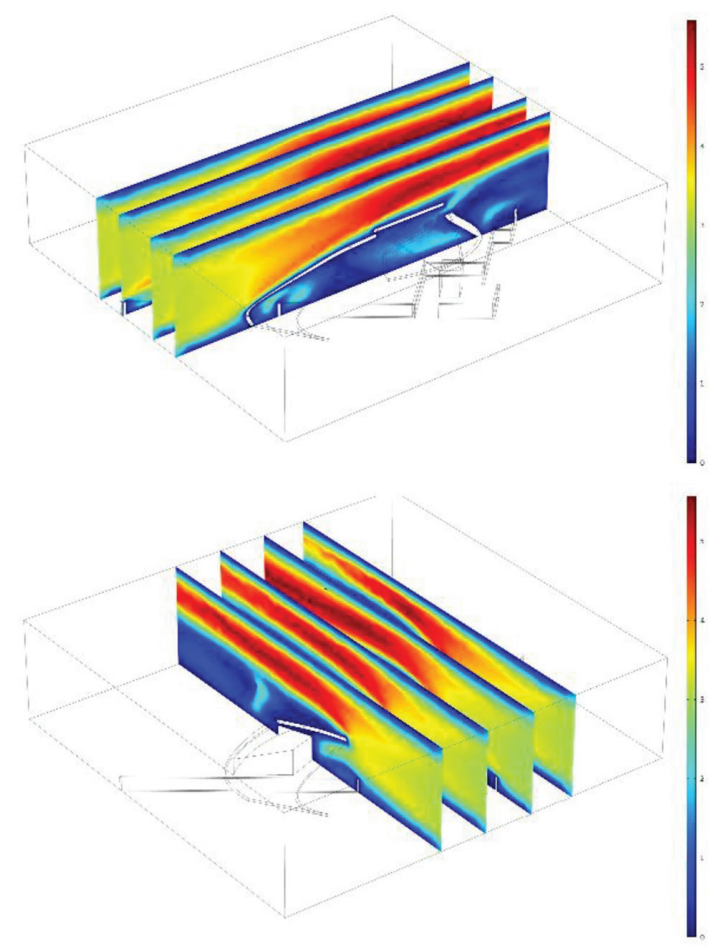

Figure 7: Tomographic slices, rainbow effect next to the top boundary. 


\section{MATERIALS AND TECHNOLOGIES}

The opportunity to travel deep in the outback was an important occasion to learn about traditional architecture and to observe an ancient, original, and completely sustainable relationship between man and nature. Over the years, these powerful geometric constructions remained unchanged in form and technology, except for the replacement of straw roofs with metal sheets as a result of modern restoration work; the use of bamboo in Cameroon, a unique building material, is widespread and used in various forms, such as column, rods, and wires. Passive systems ensuring living comfort are part of the technical-cultural heritage of these populations such as the adobe brick in Tanzania, which guarantees a great thermal mass. Over the centuries, they have developed 'low-tech' solutions in order to fight the severe climate of these areas, but these good practices have recently been replaced with concrete, considered a more modern material, without caring of its effective sustainability. For the design of the Women Meeting Centre, this consideration has proved to be an inspiration and, at the same time, the recovery of traditional construction knowledge was desired. All of this resulted in a dry-assembled mesh made entirely of bamboo pipes, an economic, natural, local resource; metal sheets were chosen for roofing and cladding, which were thermally and acoustically insulated with coconut fiber $(50-\mathrm{mm}$ thickness, $\lambda=0.045 \mathrm{~W} / \mathrm{mK})$ in order to give a modern style and, in particular, to encourage one of the few thriving local industries. The demand for electricity was met with a photovoltaic plant of $3,5 \mathrm{kWp}$ composed of modules placed on supports in the park; it includes protection from the sun. The overall energy balance is met by collecting rainwater in buried tanks with a capacity of 40,000 L, and cooling the pavilion with a geothermal heat exchanger in addition to the passive ventilation system described above.

At the same time, outdoor comfort has also been satisfied by planting trees, mainly Mangifera indica, which can grow up to 20-35 metres in the tropical climate with a canopy that can reach up to 10 meters in diameter, providing good shade on pedestrian paths. Other widely used plants were Cymbopogon citratus and C. nardus, which produce a natural mosquito repellent, necessary in a place where malaria is still not controlled. A system of constructed wetlands for disposal of greywater was also planned for the garden.

The Boma Community Service project is characterized in the same way by local materials, inexpensive, readily available on site and easy to work. The choice of the best materials was made according to their physical properties of emissivity and albedo, namely the ability to radiate energy and to reflect the incident radiation. The external walls are made of sun-dried adobe brick, due to its thermal mass, which can mitigate the overhang of temperatures between interior and exterior resulting an excellent thermoregulator. Following the same principles, the floor is made of beaten earth on a foundation of river pebbles or large granite platforms. The outer metal sheet cover is fixed through a spatial reticular of welded steel rods and the use of several sunscreens and shelter structures made of tropical wood (which Tanzania is being a great producer) provide a bigger shaded area. Today the entire community doesn't receive any type of energy, so they live without the use of electricity, making light and cooking only with firepans. In part, that characterizes their lives since long time and it's belong to their tradition but the availability of light in the evening hours would save them a great deal of timber and the time of its research. For that reason, the project provides a little photovoltaic plant of $1,5 \mathrm{kWp}$ and the water requirement is fulfilled by two tanks of 35,000 L.

\section{RESULTS}

The use of parametric CFD software allowed the modeling phases to be combined with the verification phases through a method of continuous computational analysis and adjustment of 
the solutions adopted. The effective validation of data extrapolated from the tomographies was instead undertaken with algorithms that follow Fanger's theory, i.e. calculating the PMV (Predicted Mean Vote) and the PPD (Predicted Percentage of Dissatisfied). Based on non-isothermal flow and heat transfer in solids and definite boundary conditions according to the representative day [7], defined as $\mathrm{U}_{0}=3 \mathrm{~m} / \mathrm{s}, \mathrm{T}_{0}=303^{\circ} \mathrm{K}, \mathrm{RH}=84 \%$ for the WMC and $\mathrm{U}_{0}=3 \mathrm{~m} / \mathrm{s}, \mathrm{T}_{0}=300^{\circ} \mathrm{K}, \mathrm{RH}=55 \%$ for the $\mathrm{BCS}$, it was possible to work on $3 \mathrm{D}$ models that restore the modification trends in real time. It is helpful, therefore, to size the roof elements (Figs. 8 and 9), to verify the operation of the extraction chimney (Fig. 10), to correct the building apertures, and more generally, control air fluxes triggered by the buildings, generally being careful to avoid significant turbulence that could worsen living comfort. For this, a maximum limit of $3 \mathrm{~m} / \mathrm{s}$ was set for internal fluxes.

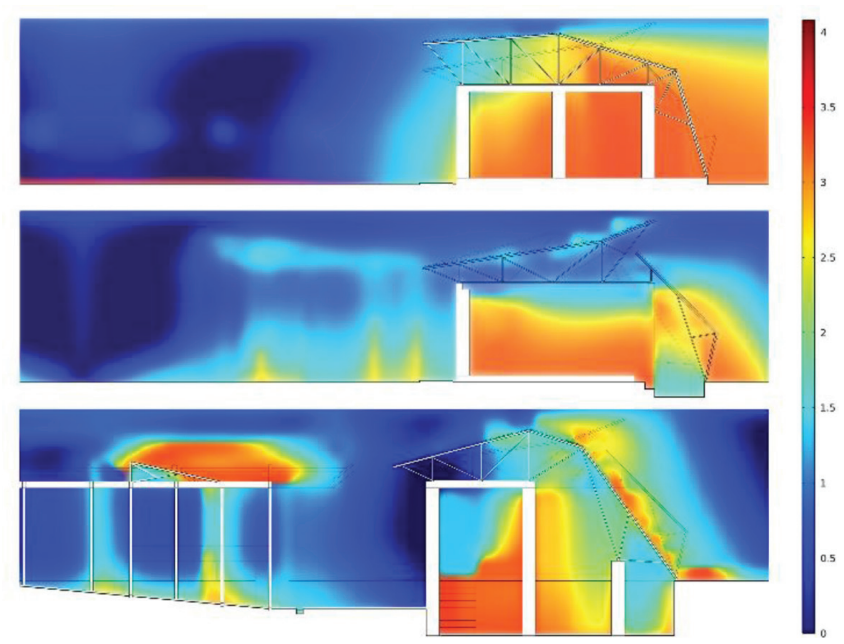

Figure 8: BCS roof study, velocity magnitude $(\mathrm{m} / \mathrm{s})$.

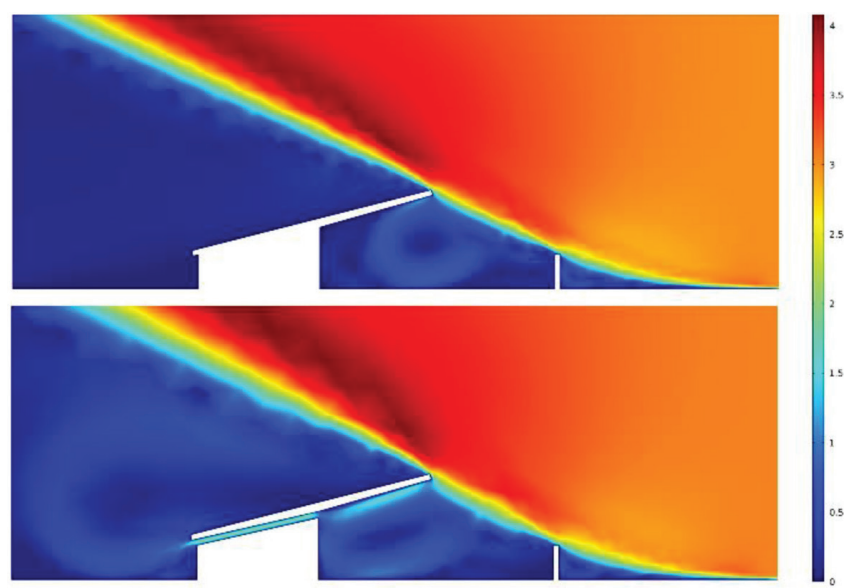

Figure 9: WMC roof study, velocity magnitude $(\mathrm{m} / \mathrm{s})$. 


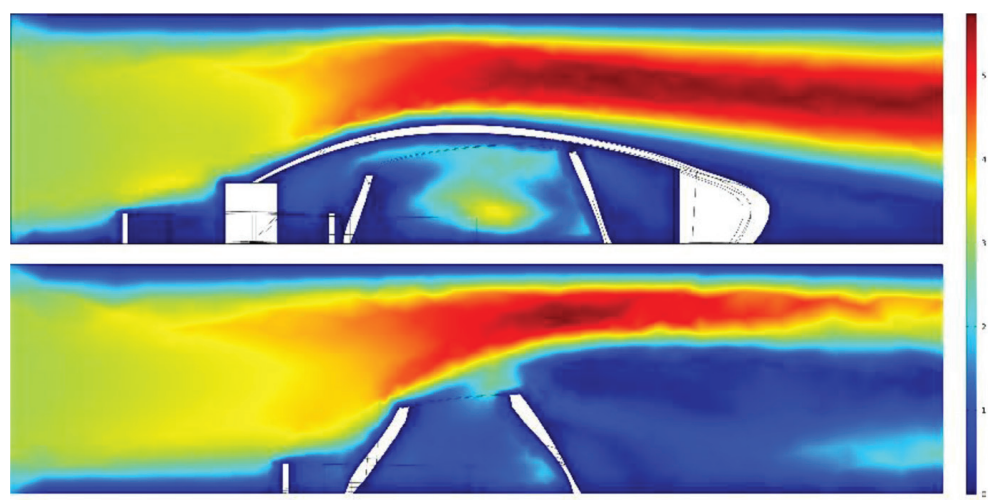

Figure 10: WMC extraction chimney, velocity magnitude $(\mathrm{m} / \mathrm{s})$.

In addition, the success of such bioclimatic design was verified by calculating the PMV and PPD thermal comfort indices. The values calculated with Fanger's algorithm, as shown in Table 1 and Table 2, indicate the good hygrothermal comfort conditions obtained from such a design, in the Women Meeting Centre as well as in the Boma Community Service.

The TENS can provide important information to assist in the design of energy-efficient, user-comfortable and environmentally friendly buildings (Fig. 11).

Table 1: PMV Validation - Women Meeting Centre, Buéa.

\begin{tabular}{llllll}
\hline Place & T & V & RH & PMV & PPD \\
\hline WMC - ENTRANCE & 29,6 & 3,28 & 84 & 0,28 & 6,67 \\
WMC - SEATS & 26,3 & 0,12 & 84 & 0 & 5 \\
WMC - HALL & 27,7 & 0,41 & 84 & 0,82 & 19,32 \\
WMC - TUB & 29,6 & 3,28 & 84 & 0,28 & 6,67 \\
CAFE - OUTDOOR & 28,6 & 0,06 & 84 & 1,48 & 50,13 \\
CAFE & 28,1 & 0,01 & 84 & 1,52 & 52,16 \\
CLASSROOMS & 29,8 & 0,44 & 84 & 1,58 & 55,78 \\
PATHS & 29,8 & 1,83 & 84 & 1,03 & 27,81 \\
\hline
\end{tabular}

Table 2: PMV Validation - Boma Community Services, Mkuru

\begin{tabular}{llllll}
\hline Place & T & V & RH & PMV & PPD \\
\hline WMC - ENTRANCE & 19,8 & 3,61 & 55 & 0,46 & 16,23 \\
WMC - SEATS & 25,1 & 1,42 & 55 & 1,58 & 55,78 \\
WMC - HALL & 24,6 & 0,25 & 55 & 1,86 & 65,65 \\
TOILETS & 18,1 & 4,25 & 55 & 0,66 & 23,3 \\
PATHS & 24,3 & 3,54 & 55 & 1,46 & 51,53 \\
\hline
\end{tabular}




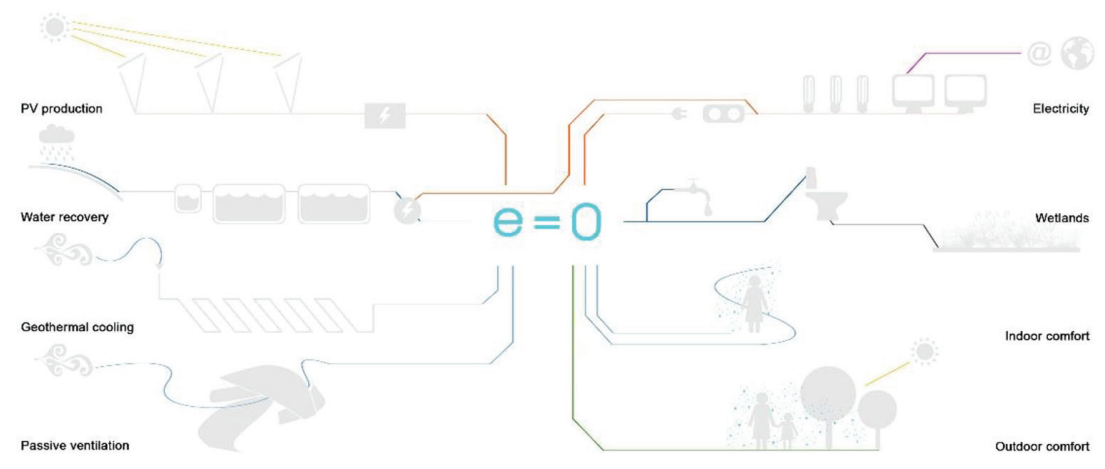

Figure 11: Women meeting centre energy balance.

\section{CONCLUSIONS}

This paper introduced the applications of TENS methodology for building design in third world countries, e.g. Buéa in Cameroon and Mkuru in Tanzania. It discussed the typical aspects that CFD simulations can contribute to a successful building design, along with validation of thermal comfort reached using Fanger's indices (PPD and PMV). The TENS tool has initiated an innovative field of investigation based on the small-scale design of open spaces, powerful in understanding the richness of micro-climatic conditions also during severe sub-Saharan hot seasons. It can be employed in the early design stages to evaluate different generic strategies and incorporate comfort requirements in architectural projects, particularly for low cost and low tech buildings.

\section{REFERENCES}

[1] Carmona, M., Tiesdell, S., Heath, T. \& Oc, T., Public places urban spaces: The dimensions of urban design. Architectural Press, Amsterdam, 2011.

[2] Kere Architecture, Primary school and extension, Gando, Burkina Faso. Lotus, 140, 2009.

[3] Tamassociati, Paediatric clinic, Nyala, South Darfur. Ecologik, 18, p. 8, 2010.

[4] Fanger, P.O., Thermal comfort. McGraw- Hill, New York, 1972.

[5] Wiley, J., Philippe Rahm meteorological architecture. AD Architectural Design, 79(3), pp. 30-41, 2009.

[6] Ottone, M.F. \& Cocci Grifoni, R., Environmental cross sectional tomography: a new approach to design and planning. PLEA 2012, Architecture and Sustainable Development, 2012.

[7] Latini, G., Cocci Grifoni, R. \& Tascini, S., The representative day technique in the analysis of thermal comfort in outdoor urban spaces. PLEA 2011, Architecture and Sustainable Development, pp. 397-401, 2011. 